\title{
The elasticity of verb meaning revisited ${ }^{*}$
}

\author{
Beth Levin \\ Stanford University
}

\begin{abstract}
This paper investigates the sources of systematic argument realization differences among two classes of manner verbs, hitting and wiping verbs. Its starting point is the hypothesis that argument realization patterns can largely be attributed to grammatical constraints on argument expression interacting with grammatically privileged properties of a verb's root. These properties include the root's ontological category and, as argued here, whether it encodes contact at a point or a region.
\end{abstract}

Keywords: argument realization, event structure, manner/result, roots

\section{The big question: Meaning and distribution}

As Fillmore (1970) and others have observed, verbs with similar meanings often show a characteristic argument realization pattern-that is, a shared pattern of morphosyntactic distribution. One insight that emerges is that 'manner' verbs such as hit and wipe show greater argument realization flexibility than 'result' verbs such as break and clean (Rappaport Hovav \& Levin 1998, 2010). In previous work, I pursue the hypothesis that these two patterns of behavior can largely be attributed to grammatical constraints on argument realization interacting with the 'ontological category' of a verb's root (Rappaport Hovav \& Levin 1998; Rappaport Hovav In press). The ontological category provides a characterization of the minimal grammatically relevant facet of a verb's lexicalized meaning - the meaning entailed across all uses of that verb. Acknowledging that the empirical landscape is more complex than studies of argument realization in the 1990s assume, here I begin to investigate the sources of systematic argument realization differences among manner verbs in the context of this hypothesis. First, I show that wipe and hit, each representative of a subclass of manner verbs, instantiate the flexibility characteristic of such verbs somewhat differently. Then, I sketch an account of their behavior that builds on Rappaport Hovav \& Levin 1998, 2005, 2010 and Levin 1999, as well as on advances in the understanding of argument realization. Due to length constraints, I only present the broad outlines of an account and leave details for the future.

* I am grateful to the audience at the Pre-SALT Workshop on Meaning and Distribution for comments. I thank Scott Grimm, Boris Harizanov, and Malka Rappaport Hovav for valuable discussion.

(C)2017 Levin 
My study is predicated on assumptions shared with many current approaches to argument realization and verb meaning. First, verb meaning as instantiated in a verb's use in a particular context is bipartite, consisting of an event schema and a root, which together constitute an event structure. That is, the verb's root-its idiosyncratic semantic content—must be distinguished from the event schemas - the basic event types - that it can be found in (Borer 2003, 2005; Goldberg 1995; Lieber 2004; Pesetsky 1995; Pinker 1989; Ramchand 2014; Rappaport Hovav \& Levin 1998). ${ }^{1}$ Second, these event structures, in turn, largely determine the verb's argument realization options. In much recent work, the relation between event structure and argument realization is taken to be trivial, in that the event structures are syntactically instantiated (Borer 2003, 2005; Harley 2005, 2010; Mateu 2012; Ramchand 2008). I do not make this assumption here, but my account could equally well be cast in an approach where the syntactic structure is the event structure.

What remains controversial is the role of the root in argument realization. Does it play a part in determining argument realization or is it 'inert' with respect to argument realization $?^{2}$ I have assumed and maintain here that some facets of the semantic content of roots are grammatically privileged. Following Rappaport Hovav \& Levin (1998) and Rappaport Hovav (In press), I take every root to have a grammatically relevant ontological category, such as result (or state) or manner. This category largely governs the event schemas the root is paired with and hence the associated verb's argument realization options. This paper takes a first look at the factors that come into play when attested argument realization options are a subset of the potential options allowed by root-event schema associations. I argue there are further grammatically privileged facets of a root's semantic content which systematically restrict the options, but acknowledge a limited role for world knowledge.

Other researchers, however, deny that roots play any part in argument realization. They suggest that roots can simply be inserted into any event schema, adopting what Rappaport Hovav (In press) calls the 'free distribution' approach (Borer 2005; Mateu \& Acedo-Matellán 2012). Two reasons are given for this approach. First, verbs are found in a wider variety of syntactic contexts than earlier work suggests (Borer 2003: 40). Second, some of the purportedly verb-specific distributional patterns, such as the greater flexibility in argument realization of manner over result roots, appear to break down (Acedo-Matellán \& Mateu 2014: 20). On the free distribution approach, all root-event schema combinations-or really syntactic frame options since many proponents assume event structures are syntacticized-are generated by the grammar; however, certain combinations are taken to be 'incompatible'

1 The bipartiteness of verb meaning can be given lexical/projectionist or constructional treatments; this issue is set aside here, but see the Appendix of Rappaport Hovav \& Levin 1998 for discussion.

2 See Ramchand 2014 for an interesting case study of light verbs aimed at distinguishing those elements of a verb's-or root's-meaning that are relevant to the syntax and those that are conceptual. 
Verb meaning revisited

(Ghomeshi \& Massam 1995: 179) in that they give rise to pragmatically infelicitous argument realizations (Borer 2003, 2005; Goldberg 1995; Hoekstra 1992; Mateu \& Acedo-Matellán 2012). Such incompatibilities are attributed to world knowledge. Although world knowledge plays a critical role in constraining a verb's argument realization options, details remain to be fleshed out.

Despite the challenges raised by proponents of the free distribution approach, I believe much is still to be learned from pushing the 'ontologically categorized roots' approach as far as possible as I do here as this forces us to identify cross-verb generalizations. These should deepen our understanding of argument realization and clarify the contribution of grammatical vs. world knowledge to the explanation of distributional patterns. At the same time, I confront the empirical challenges that this approach faces by examining a wider set of data: two manner verb subclasses.

$\$ 2$ reviews familiar empirical argument realization patterns involving the verbs break and hit and uses them to introduce the ontological categories of manner and result. $\S 3$ expands the empirical landscape by setting out the argument realization options characteristic of two subtypes of manner verbs represented by hit and wipe. $\$ 4$ sketches the basics of my approach to event structure and argument realization. $\S 5$ shows how it gives rise to the observed argument realization patterns, once an additional facet of root semantic content is acknowledged. $\$ 6$ extends the approach to more complex event structures and their associated argument realization options by appealing in a limited fashion to world knowledge.

\section{The empirical landscape: From hit and break to manner and result}

Fillmore's (1970) case study of the English verbs hit and break provides compelling reasons to believe that verbs might have a distributional signature, that is, a characteristic set of argument realization options. Although both hit and break have transitive uses that optionally can occur with an instrumental phrase, as in (1), the behavior of the two verbs otherwise diverges. Thus, break but not hit shows the causative alternation as in (2), while hit but not break is found in 'possessor raising' contexts such as the (b) sentences in (3) and (4), which can be related to the non-possessor raised construction in the (a) sentences. This difference is noteworthy since the possessor-possessum relation exists independent of event types. There are further differences. For instance, hit but not break is found in the conative construction in (5), where the object of the transitive use is now in an at phrase. The conative construction suggests that the action was attempted, but did not necessarily succeed: thus, (5b) does not necessarily imply that contact occurred, simply that the action that might have resulted in contact was attempted.

(1) The boy broke/hit the window (with a ball). 
(2) a. The boy broke the window./The window broke.

b. The boy hit the window./*The window hit.

(3) a. The boy hit the toddler's back.

b. The boy hit the toddler on the back.

(4) a. The boy broke the cup's handle.

b. * The broke the cup on the handle.

a. * The boy broke at the window.

b. The boy hit at the window.

The importance of these patterns is underscored by the observation that break and hit each share their distributional signature with other semantically similar verbs, as in (6). The verbs with the same distributional signature as hit qualify as surface contact verbs, while those with the same distributional signature as break qualify as change of state verbs.

a. Break verbs: bend, fold, shatter, crack, ...

b. Hit verbs: slap, strike, bump, stroke, ... (Fillmore 1970: 125, (15)-(16))

Juxtaposing hit and break is effective precisely because certain happenings in the world can be described by either verb. Consider a scenario where a vandal throws a rock at a flower pot and it breaks. This scenario could be described as either a hitting or a breaking event, as in (7). However, each sentence captures a distinct facet of this scenario. The hitting event description is 'silent' about the ultimate effect on the flower pot, while the breaking event description is 'silent' about how the change to the flower pot came about. Thus, the breaking sentence (7a) is consistent with the scenario described here, but could also be used to describe a scenario where a flower pot is broken in another way, as in (8a). Similarly, the hitting sentence (7b) is consistent with the scenario described here, but it could also be used in a scenario where the ball simply bounces off the flower pot without breaking it, as in (8b).

(7) a. The vandal broke the flower pot with a rock.

b. The vandal hit the flower pot with a rock.

a. The vandal broke the flower pot by dropping it on the ground/throwing it at the wall/pounding it with a hammer.

b. The vandal hit the flower pot with a rock, but nothing happened to it.

Moving beyond Fillmore's study, Rappaport Hovav \& Levin (1998, 2010) show hit and break each represent larger classes of verbs. The verb break is representative of verbs with result roots. Such roots specify a state; this state often results from an 
Verb meaning revisited

action (e.g., 'broken', 'cut'), but could also exist independent of a prior action (e.g., 'red', 'soft'). In contrast, hit is representative of verbs with manner roots. Such roots specify a manner characteristic of an action, and their semantic content is discussed in $\$ 4$. Result verbs are 'silent' about how the result comes about, while manner verbs are 'silent' about whether the action has any effect, as (8) illustrates.

The manner vs. result root distinction is pervasive, cutting across many semantic fields. Within the semantic field of verbs describing damaging events there are manner verbs such as hit and pound and result verbs such as break and crack. Within the field of verbs describing combining events there are manner verbs such as shake and stir, which name actions generally carried out to combine two or more substances, although they need not have this effect, and there are results verbs such as blend and combine, which are silent about how the result they name comes about. In the semantic field of verbs describing putting events, manner smear and pour can be contrasted with result cover and fill. Other semantic fields that include both manner and result verbs include killing, ${ }^{3}$ removing, and speaking.

Manner and result verbs - or roots - each have their own distributional signatures (Rappaport Hovav \& Levin 2005, 2010), which are generalizations of the distributional signatures of hit and break. Generalizing from the data presented, break requires that the argument that the result is predicated of - the patient-be expressed. Thus, result verbs are not found in unspecified object contexts. That is, (9) cannot mean that the child broke some unspecified things. Nor are result verbs found in nonselected object resultatives, as in (10). Here on the intended meaning, where the child's propensity to break things causes his parents distress, his parents is not the object of the verb break in isolation (*break his parents), while the intended object ('things') is left unexpressed (cf. the comparable example with the hitting verb drum in (12)). Result verbs, however, are found in selected object resultatives, as in The child broke the vase to smithereens, where the vase is understood to break.

(9) *The clumsy child broke.

(10) *The clumsy child broke his parents to distraction.

As the break data illustrates, expressing the patient alone is not sufficient for the well-formedness of a sentence with a result verb. If it were, break would be expected to be found in the conative and possessor raising constructions. Setting aside the causative alternation, the key argument realization generalization holding of break in particular and result verbs in general is not only that the patient be expressed, but that it be expressed as an object (Rappaport Hovav \& Levin 2005). (I focus on transitive uses of break, but in the absence of a cause argument, the patient must surface as the subject of an unaccusative intransitive use.)

3 But see Beavers \& Koontz-Garboden 2012 for arguments that purported manner of killing verbs also lexicalize a result and Rappaport Hovav In press for arguments that drown is actually a result verb. 
Manner verbs, in contrast, lack such restrictions. Consider hit, which takes two arguments: an 'effector' (Van Valin \& Wilkins 1996) — the argument realized as the subject — and a 'force recipient' — the argument that the force is directed at with a hitting verb (Rappaport Hovav \& Levin 2001: 786). This verb in particular and manner verbs in general do not require that their force recipient be expressed. They may be found in unspecified object contexts, as in (11), or in nonselected object resultatives, as in (12). ${ }^{4}$

(11) No players should hit until the players in front are out of range ... (Etiquette and Slow Play, Mount Gambier Golf Club, Australia; http://www.mtgambiergc.com.au/golf/golf-etiquette.html)

(12) Kim drummed her fingers raw.

Furthermore, when the force recipient is expressed, manner verbs are not so picky about how it is expressed. For instance, hit allows its force recipient to be expressed in an at PP, as in the conative construction, in (5b). More generally, manner verbs show various object alternations. For example, hit shows the with/against alternation (Levin 1993: 67-68), illustrated in (13). The two variants are near paraphrases; in the (a) sentence the force recipient is the object, while in the (b) sentence it is expressed in a locative PP, while the instrument is the object.

(13) a. The boy hit the window with a stick.

b. The boy hit the stick against the window.

In contrast, result verbs, including break, do not show this alternation, as the relevant sentences are not paraphrases. Consider the pair of break sentences in (14); here, the object in each construction is understood as the patient, consistent with the argument realization constraint on patients.

a. The boy broke the fence with a stick.

b. The boy broke the stick against the fence.

As this section shows, the notions 'manner' and 'result' matter to argument realization: they figure in the statement of systematic and pervasive generalizations. The bottom line is that result roots show a more limited distribution overall than manner roots. With these 'coarse-grained' distributional asymmetries tied to 'manner' and 'result' as a backdrop, the next section presents 'medium-grained' distributional differences that arise among verbs with manner roots.

4 Due to pragmatic constraints on unspecified object constructions, some manner verbs are only felicitous in such constructions with appropriate and explicit contextual support (Brisson 1994; Rappaport Hovav \& Levin 1998: 117). The verb hit is one of these, while the hitting verb peck requires less support (e.g., The bird pecked). 
Verb meaning revisited

\section{The empirical landscape expanded: Hitting vs. wiping}

Just as hit and break are chosen by Fillmore for his case study because they each represent an entire class of verbs, specifically, manner and result verbs, the verbs hit and wipe are chosen for the case study at the heart of this paper because they each represent a distinct subclass of surface contact verbs, verbs describing making contact with a surface in some manner. These two verbs show shared propertiesprecisely those properties which are characteristic of manner verbs and which set them both apart from break and other result verbs. For example, neither places restrictions on the realization of its force recipient in the way that break does on its patient. However, in this section I show that each verb manifests the manner verb properties in its own way; in $\$ 5$ I return to these verbs and propose a property of their roots which these distinct distributional signatures can be traced to.

\subsection{Surface contact verbs: Similarities}

Like manner verbs in general, wiping verbs permit a wide variety of argument realization options, including some shared with hitting verbs. Both hitting and wiping verbs are found in intransitive uses with an understood unspecified object, as in (15). Both are also found in nonselected object resultatives and the conative construction, as in (16) and (17), respectively.

(15) a. Kim hit and hit.

b. You wash and I'll wipe.

(16) a. Kim drummed her fingers raw.

b. Cinderella scrubbed her fingers raw.

(17) a. Kim hit at the mosquito.

b. Kelly wiped at the sticky counter.

Both hitting and wiping verbs can be found with an NP that expresses an instrument. The instrument may be expressed in a with phrase as in the (a) sentences of (18) and (19) or, specific to surface contact verbs, as an object as in the (b) sentences. These two options instantiate the with/against alternation introduced in $\S 2$; despite the name, the against construction allows PPs headed by some other locative prepositions, including over, as in (19b).

(18) a. Kim hit the fence with a stick.

b. Kim hit the stick against the fence.

(19) a. Sam wiped the table with a damp cloth.

b. Sam wiped a damp cloth over the table. 
Taken together, these examples suggest that both hitting and wiping verbs need not realize a specific argument as their direct object. Options for their object include the force recipient as in (a), the instrument as in (b), or a nonselected object as in (c).

(20) a. hit the table

b. hit the stick against the fence

c. drum one's fingers raw

(21) a. wipe the table

b. wipe the cloth over the table

c. scrub one's fingers raw

Wiping verbs also allow their object to be the material found on the force recipient as in wipe the crumbs off the table, an option discussed further in \$3.2.

Thus, this initial comparison of the argument realization properties of hitting and wiping verbs shows that they both manifest the key properties of manner verbs-that is, those properties which distinguish them from result verbs.

\subsection{Surface contact verbs: Differences}

Despite the significant similarities, hitting and wiping verbs diverge in some respects. The key differences revolve around the force recipient. The first difference is in aspectual interpretation and does not involve argument realization. It involves the role of the force recipient when expressed by a quantized (i.e. delimited) NP in determining the telicity of a sentence. With hitting verbs a quantized force recipient is never understood as an incremental theme (Dowty 1991: 567); that is, these verbs do not allow telic interpretations in their 'bare' transitive uses, as shown in (22) and (23) using standard (a)telicity diagnostics. Some hitting verbs like hit can refer to either a single or multiple instances of contact, while others like pound, necessarily refer to multiple instances of contact; however, this difference in the natural durativity of the event denoted has no effect on the availability of telicity.

(22) a. Kim hit the fence for 5 minutes. (only on the iterated interpretation)

b. \# Kim hit the metal in 5 minutes.

a. Kim pounded the metal for 5 minutes.

b. \# Kim pounded the metal in 5 minutes.

In contrast, with wiping verbs a quantized force recipient may be understood as an incremental theme, though it need not be (Rappaport Hovav \& Levin 2005: 281). The availability of both telic and atelic interpretations is shown in (24). 
Verb meaning revisited

(24) a. Sam wiped the table in one minute flat.

b. Sam wiped the table for an hour.

Wiping verbs then qualify as potential or 'latent' incremental theme verbs (Tenny 1992: 20). They describe actions that can in principle be applied indefinitely to the force recipient even when it is delimited; that is why a sentence like Sam wiped the table may be atelic. However, the force recipient can be understood as an incremental theme when it has a delimited area: this area 'measures out' and delimits the event, so that the event is complete when the action covers the entire area. ${ }^{5}$

Although a wiping event requires a surface as force recipient, wiping verbs may take an additional argument denoting some material or substance found on this surface (Levin \& Rappaport Hovav 1991), typically material that the action is intended to remove.

a. Terry is wiping the counter.

b. Terry is wiping the stains (off the counter).

Hitting verbs, in contrast, do not take an additional argument denoting a material or substance on a surface.

Although the force recipient might be considered the 'normal' direct object of a wiping verb, the material can also be the direct object. Usually, the material is only felicitous as the object when it cooccurs with a directional complement, which may express a source, which coincides with the force recipient, as in (26), or may express a goal, as in (27). ${ }^{6}$ Taking these observations together, it appears that the directional complement licenses the material as object (Rappaport Hovav \& Levin 1998; see $\S 6.2$ for discussion). When the material is the object, it too can be the incremental theme by virtue of its physical extent when quantized, as in (26).

a. Terry wiped crumbs off the table for three minutes. (atelic)

b. Terry wiped the crumbs off the table in one minute flat. (telic)

(27) Terry wiped the crumbs into the sink.

5 Wiping and comparable manners are often carried out to achieve a particular result, often cleanliness; this result, even if implicit, can provide another basis for delimiting the event. That is, Sam wiped the table can receive a telic reading when understood as 'Sam cleaned the table' (see Rappaport Hovav \& Levin 2005: 281). On this reading, the event ends when the table reaches a state of cleanliness. If the cleanliness is taken to be instantiated gradually over the surface of the table, then the table is the incremental theme; however, if the cleanliness is seen as increasing over time over the entire table, then the table is what Dowty (1991: 569) calls a holistic theme.

6 Wiping verbs differ as to whether they can take a bare material object; compare Sam raked the leaves to *Terry wiped the crumbs. The licensing conditions need to be identified before an analysis of such examples can be proposed. 
Furthermore, although a material argument, if present, is most often expressed as an object, it may sometimes be expressed in an of phrase when the force recipient is the direct object, as in (28), which contrasts with (29).

(28) We finished the creamy custard, scraping the cup of its thick, bittersweet chocolate sauce ... (D. Pergamaent, Best Trattoria in Rome? Let the Debate Begin, Travel Section, The New York Times, March 22, 2009, p. 11)

(29) He scraped the thick, bittersweet chocolate sauce from the cup.

Due to these two expressions of the material argument, wiping verbs are said to participate in the locative alternation. ${ }^{7}$

(30) a. We scraped the sauce from the cup.

b. We scraped the cup (of sauce).

Although wiping verbs show some argument realization options that are unavailable to hitting verbs, there is an option open to hitting but not wiping verbs. Only hitting verbs allow possessor raising, as shown in (31).

(31) a. Kelly hit me on the arm. (cf. Kelly hit my arm.)

b. * Kelly wiped me on the arm. (cf. Kelly wiped my arm.)

In summary, even among manner verbs, there are subclasses whose members show systematic differences in argument realization. Specifically, hitting and wiping verbs show distinct distributional signatures; nevertheless, the distributional signature of verbs in both classes satisfies the general argument realization criteria characteristic to manner verbs. This constellation of properties suggests that an apparently grammatically privileged facet of the semantic content of the relevant roots is behind the distinct distributional signatures; this facet must be in addition to the root's common, manner ontological category. \$5.2.1 identifies what it is. First, I sketch the basics of the account of event structure and argument realization I adopt.

\section{The basic ingredients of event structure}

In order to understand how the distributional signatures emerge, it is necessary to lay out some basic assumptions I am making about event structures - the event representations associated with particular verb uses - and the principles that associate them with syntactic structures. My approach takes its inspiration from Rappaport

7 There is controversy in the locative alternation literature about whether verbs other than the result verbs clean, clear, and empty allow such of phrases (Hook 1983: 187-188, 190; Levin \& Rappaport Hovav 1991: 144-145; Segal \& Landau 2012: 254-257). As (30) shows, at least some wiping verbs do, although the licensing conditions remain to be clarified. Other languages allow this option more freely (Alexiadou \& Anagnostopoulou 2013 on Greek; Segal \& Landau 2012 on Hebrew). 
Verb meaning revisited

Hovav \& Levin (1998), while taking into account advances in our understanding. As mentioned in $\S 1$, event structures and syntactic structures could be one and the same, as in approaches that syntactically instantiate event structures (Borer 2005; Harley 2005, 2010; Mateu 2012), making argument realization trivial, or they could be distinct. I treat them as distinct, but what matters is that there are restrictions on the realization of certain event structure participants, however they are implemented. Furthermore, I do not take a position on the appropriate form of event structure; I simply lay out the minimal assumptions that are necessary. I believe these assumptions could be instantiated in various ways, including via predicate decompositions such as those found in Rappaport Hovav \& Levin 1998 and some of their subsequent work or via syntacticized event structures such as those found in Alexiadou, Anagnostopoulou \& Schäfer 2015; Harley 2005, 2010, and others. Overall, my goal here is to sketch the outlines of an account.

A verb's meaning as instantiated in a verb's use in a particular context-i.e. its event structure - is taken to be bipartite, consisting of an event schema and a root. I assume languages have a limited inventory of event schemas, encompassing the basic event types that can be encoded. Event schemas fall into two major types: simple event schemas and complex event schemas, which consist of two simple event schemas. The simple event schemas include schemas for states, events of scalar change, and activities. An event of scalar change involves a change in the value of a scalar-valued attribute of an entity, whether the type of property lexicalized by an adjective or by a position along a path. I realize that the term 'activity' has several uses, most prominently receiving an aspectual definition; however, I use this term here more broadly to cover typically dynamic events that involve a manner-roughly, what Rappaport Hovav \& Levin (2010) and Rappaport Hovav (2014) call 'nonscalar changes'. According to them, nonscalar changes lack a single, privileged scale of change, but rather typically involve multiple cooccurring changes. Aspectually, nonscalar changes encompass both traditional activities in the Vendler 1957 sense and semelfactives (Levin 1999). Complex event schemas consist of a causing event and a caused event. I focus on complex event schemas whose causing event is an activity and whose caused (or result) event is a scalar change (Dowty 1979; Levin 1999; Levin \& Rappaport Hovav 1999; McCawley 1971; Morgan 1969; Rappaport Hovav \& Levin 1998). These represent the most complex event schemas since as argued by Goldberg (1995) and Tenny (1994) in the context of resultative constructions, a well-formed event structure can only include one scalar change. Complex event structures are discussed further in $\S 6$.

Roots are lexically associated with a phonological shape, which is not relevant here, and semantic content. The general assumption is that most of this semantic content is kept 'outside' of the grammar (Grimshaw 2005). For instance, change of state verbs show the same distributional signature independent of the result 
state involved. However, I assume that a few facets of this semantic content are grammatically privileged - that is, accessible to the grammar-and one goal of the remainder of this paper is to pinpoint what these are. Specifically, Rappaport Hovav \& Levin (1998) propose that as a consequence of its semantic content a root has a grammatically relevant ontological category chosen from a fixed set of options; see $\S 1$ and $\S 2$. This category is one of the grammatically privileged facets of the semantic content. Roots are inserted into event schemas which are compatible with their ontological category. For instance, Rappaport Hovav \& Levin's (1998: 109) Canonical Realization Rules were designed to ensure this. Through its association with an event schema, a root gives rise to an event structure with specific content.

As noted in $\S 2$, two ontological categories of roots are of interest here, manner and result. Informally speaking, result roots specify a state, and, henceforth, I refer to these as state roots. This label is preferable to 'result' as the same root is shared by an adjective and a related verb, such as $\operatorname{dim}_{A}$ and $\operatorname{dim}_{V}$ or narrow $w_{A}$ and narrow $_{V}$; see also Rappaport Hovav In press. But even this characterization glosses over important details. Rappaport Hovav \& Levin (2010: 28) propose that result verbs are best described as verbs of scalar change - that is, they specify a change in the value of a scalar-valued attribute of an entity; concomitantly, Rappaport Hovav \& Levin (2010: 28) propose that the roots of result verbs specify scalar changes. However, even this improved characterization does not acknowledge that there are adjective-verb pairs with a shared root. In order to capture this observation, it is more accurate to say that a state root lexicalizes critical components of a scale associated with a scalar-valued attribute. When the root is inserted into an event schema (in syntactic terms, combined with categorizing little $v$ or little $a$; see Alexiadou et al. 2015, Kratzer 2000), then a notion of change or of state is combined with the root's lexicalized content to derive the appropriate meaning; that is, the event schema itself contributes the notion of change. Turning next to manner roots, I assume that the semantic content of such roots typically includes what Jackendoff (1990: 34) calls an 'action pattern', which he proposes might be encoded using Marr \& Vaina's 1982 '3-D models'. Rappaport Hovav \& Levin (1998) suggest that state roots fill argument positions in event schemas (often instantiated in syntacticized approaches as being a complement of a copular predicate in a small clause structure), while manner roots are event modifiers - that is, modifiers of primitive predicates in event schemas that take the form of a lexical decomposition. I do not pursue the specifics of this proposal here, though subsequent work that adopts syntacticized event structures also adopts the idea that manner roots can be event modifiers (Harley 2005; Mateu \& Acedo-Matellán 2012). What matters is that state roots are associated with state or scalar change event schemas or else are lexicalized by adjectives, while manner roots are associated with activity event schemas.

As discussed in Hay, Kennedy \& Levin 1999, Kennedy \& Levin 2008, Krifka 
Verb meaning revisited

1998, and Ramchand 1997, there are several types of scalar change. The two types lexicalized by verbs - or more accurately their roots — are relevant here (Rappaport Hovav 2014; Rappaport Hovav \& Levin 2010). ${ }^{8}$ One type involves a property scale - a scale defined by a scalar-valued property of an entity such as its size, temperature, or brightness; such scales are lexicalized by the roots of 'deadjectival' verbs such as brighten, warm, and widen, as well as by verbs such as break and freeze. The other type involves a path scale - a scale defined by the path an entity may move along; such scales are lexicalized by the roots of directed motion verbs such as arrive, ascend, come, and exit. ${ }^{9}$ State roots may fully or partially lexicalize the components of such scales; Rappaport Hovav \& Levin 2010 and especially Rappaport Hovav 2014 discuss the components of these scales further.

Rappaport Hovav \& Levin (1998) propose well-formedness conditions on the syntactic realization of event structures. These conditions are intended to 'reflect assumptions common in the literature that elements in the semantic representation must be syntactically encoded, and that the syntactic representation must be fully interpreted' (1998: 112). Their focus is on the elements of the event schema, but based on subsequent research I extend the intuition and propose that roots also impose conditions on argument realization. I suggest that grammatically privileged material lexically encoded in a root must be 'instantiated' in an argument (Rappaport Hovav \& Levin 2010), although I do not delve into the relation between this condition and our earlier proposals (i.e. whether the earlier conditions are reducible to the new one or whether both are necessary). For state roots, the patient-the event participant that the scalar-valued attribute or the associated scalar change is predicated of must be expressed. I suggest this 'patient realization condition' arises because to know that a state holds requires looking at the entity it holds of. I leave aside precisely why the patient must be expressed as an object (including here the subject of an unaccusative verb). Although as $\$ 2$ points out, manner verbs do not impose as stringent requirements on the realization of their arguments as result verbs, I

8 The notion of scale is first brought to prominence in work on telicity since scales figure in its calculation (Dowty 1991; Hay et al. 1999; Kennedy \& Levin 2008; Krifka 1998; Ramchand 1997; Tenny 1992, 1994). Work on telicity identifies a third type of scale, an extent scale, which is associated with incremental themes. Such scales are not lexicalized by verbs or their roots (Rappaport Hovav 2014: 278-281; Rappaport Hovav \& Levin 2005); rather, they are introduced by the argument of verbs of certain types through their spatial extent; see also $\$ 5.2 .1$.

9 As mentioned, directed motion verbs are also scalar change verbs; however, these verbs are not relevant here so they are not discussed further. These verbs describe changes along a path scale-a scale defined by the path an entity moves along. Their roots lexicalize critical components of such scales, but few have roots that lexicalize all the components that define such a scale (Rappaport Hovav 2014; Rappaport Hovav \& Levin 2010). For instance, ascend's root lexicalizes the direction of motion along a path, but not the goal of motion, which must be expressed separately or inferred from context. 
propose that they too must realize an event participant that 'instantiates' the manner encoded in their root. In fact, an observer can determine the action pattern encoded in a manner root from the actions of an event participant. For hitting verbs, this participant is the effector; the manner cannot usually be determined from the force recipient. I previously chose the label 'effector' because in general the participant demonstrating the action pattern qualifies as an effector in the sense of Van Valin \& Wilkins 1996. One reason for preferring this term is that not all manner verbs take animate, agentive arguments; consider sound emission verbs and certain manner of motion verbs. Again, I leave aside why the effector is realized as a subject.

\section{Accounting for the distributional signatures}

In this section and the next I sketch how the distributional signatures of hitting and wiping verbs arise. I keep the presentation informal, but a more formal instantiation should be possible, whether done with syntactically instantiated event structures or not. I begin with change of state verbs and then turn to surface contact verbs.

\subsection{Change of state_-or scalar change_-verbs}

Change of state verbs are scalar change verbs: they describe a change in a scalarvalued property of an entity. Leaving aside the technicalities of scalar change, I simply treat change of state verbs as having a state root which is paired with an event schema representing an event of scalar change. I further restrict myself to causative events of scalar change, which involve complex event structures, as such events are the most relevant to hitting and wiping verbs. In a causative event of scalar change, the argument which the scalar change is predicated of must be expressed due to the patient realization condition and further it must be expressed as an object. As a consequence, causative scalar change verbs cannot be found with unspecified objects or nonselected objects, nor can they be found in constructions where anything but their patient argument is the object. Given this rigidity in object choice, they are also not found in object alternations. Thus, even though some change of state verbs are found in the surface syntactic frames associated with the with/against alternation as illustrated in (32), as discussed in $\$ 2$ they do not exhibit the alternation, but rather each syntactic frame associates the scalar change with its object. Thus, in (a) the fence is understood to break, while in (b) the stick is.

(32) a. The boy broke the fence with a stick.

b. The boy broke the stick against the fence. 
Verb meaning revisited

\subsection{Surface contact verbs: Basic distributional properties}

Next, I confront many of the argument realization properties of hitting and wiping verbs laid out in $\S 2$ and $\S 3$, as well as some additional ones. First, in $§ 5.2 .1$ I identify some properties of the manner roots of hitting and wiping verbs that bear on argument realization. Then, in \$5.2.2 and \$5.2.3 I turn to argument realization options that reflect simple event structures. In $\S 6$ I consider further argument realization options that involve complex event structures.

\subsubsection{On the nature of hitting and wiping roots}

As surface contact verbs, hitting and wiping verbs describe events of making contact with a surface in that manner which is distinctive to each verb - that is, that characterizes its root. Since the argument realization options of these two types of verbs reflect properties of their roots, this section examines what is distinctive about them.

I begin with a basic property of surface contact verbs that sets them apart from many other manner verbs. First, not all manner verbs are transitive like surface contact verbs; consider, for instance, manner of motion verbs or sound emission verbs. Levin (1999) argues that this property should be attributed to their root: the semantic content of the root of a surface contact verb brings with it or 'licenses' not simply an effector, but a second event participant, the surface or force recipient. Levin (1999) calls this second participant a 'constant participant', where 'constant' is an earlier term for 'root'; here I call it a 'root' participant. She uses this label since the simple activity event schema only necessarily involves one participant, which is identified with the effector, and thus the second participant would be licensed simply by a root. Yet this second participant is essential: without a surface, the action lexicalized by a surface contact root simply cannot be performed. ${ }^{10}$

Surface contact verbs have roots that lexicalize a manner which involves the mode of application of a force by an effector to a surface. The distinct distributional signatures of hitting and wiping verbs must arise from some facet of this manner. In order to pinpoint what this facet is, I examine the inventories of English hitting and wiping verbs. Such an examination leads to the identification of dimensions of similarity and variation in verb meanings both within each class and across the two classes; these in turn should offer insight into what is distinctive about their manners.

Compared to some languages (Levin 2015), English has a fairly large inventory of hitting verbs, which includes several readily identifiable subclasses; it also has a reasonable number of wiping verbs, which fall into many of the same subclasses. This similarity suggests that these shared subclasses reflect properties of surface

10 An exception among surface contact verbs is kick. This verb lexicalizes a particular motion of a leg as in The horse kicked, but does not entail that it make contact. 
contact events in particular and perhaps even of manner events in general. Thus, both the hitting and wiping verb classes include verbs — and hence roots - that make reference to the instrument used, either a body part (e.g., claw and slap among the hitting verbs; lick and suck among the wiping verbs) or tool (e.g., club and hammer among the hitting verbs; mop and sponge among the wiping verbs); I take instrument to be a subtype of a more general manner component. Among verbs that do not lexically specify an instrument, there are differences related to the intensity or 'degree' of force used (e.g., tap vs. beat and whack among the hitting verbs; wipe vs. scour and scrub among the wiping verbs), as well as to whether the force is necessarily applied multiple times or not (e.g., hit vs. pound among the hitting verbs; $d a b$ vs. scrub among the wiping verbs).

There are two ways in which the manners lexicalized by hitting and wiping verbs differ from each other. Members of a prominent subclass of hitting verbs take their names from the sound made on impact (e.g., bang, clink, thud, thump, thwack, whack); the nature of the sound reflects the nature of the impact, typically the degree of force used (e.g., clink vs. thwack); see Richardson 1983 and Stringer 2011: 18. There do not seem to be comparable wiping verbs. The source of this difference most likely lies in a second difference between wiping and hitting verbs. Unlike hitting verbs, wiping verbs lexicalize action patterns that cannot be defined with respect to a single point on a surface; rather, they involve particular patterns of motion over a surface. Consider, for instance, the verbs rub and wipe, which denote actions which differ not only in the amount of force applied to the surface, but also the characteristic pattern of movement over the surface: rubbing involves fairly small back and forth movements made while exterting a fairly strong pressure on the surface, while wiping involves longer, broader strokes which are more lightly applied to the surface. Most likely, sounds are not typically informative about such patterns of motion and, thus, wiping verbs do not take their names from sounds.

Based on this survey of verb inventories, I propose that the key difference between the members of the hitting and wiping classes - and thus their roots-is whether the locus of contact is a point or a region. Hitting roots-and eventsinvolve impact at a point —or what is conceptualized as a point. Wiping roots-and events-involve contact over a necessarily extended area. As I now show, key differences in the distributional signatures of hitting and wiping verbs can be tied to this property. Thus, I assume that this facet of the root is accessible to the grammar. However, other facets of the semantic content of the manner in hitting and breaking roots such as the instrument used, the intensity of the contact, and the iterated vs. punctual nature of the contact, are not grammatically privileged in this way: they do not bear on argument realization. I return to the larger point in the conclusion. 
Verb meaning revisited

\subsubsection{Accounting for the basic paradigms: wipe}

I now turn to many of the argument realization options characteristic of the verb wipe introduced in $\S 3$, showing how they emerge given the assumptions laid out in $\S 4$ and $\S 5.2 .1$. This verb has a manner root, which is basically associated with a simple activity event structure. Furthermore, due to the action pattern it specifies the root licenses two event participants. The first, the effector, as the participant that instantiates the root's distinctive action pattern must be expressed; specifically, effectors of activities are expressed as subjects; see $\S 4$. The second participant is the surface - or force recipient. As mentioned in \$4, wipe's root, as a manner root, does not impose constraints on the expression of its force recipient (contrasting with a state root, which requires the patient to be expressed). Thus, the force recipient need not be expressed. Concomitantly, wipe can be found in the unspecified object construction, where it lacks an object as in (33), which simply describes the performance of the activity. Furthermore, if the force recipient is expressed, there are no constraints on its expression. It may be realized as an object, as in (34), or it may be realized in an oblique phrase, as in (35), giving rise to the conative construction.

(33) Sam wiped.

(34) Sam wiped the table.

(35) Sam wiped at the table.

Given the nature of wipe's root, the surface must be understood as a region. This property underlies another property discussed in $\$ 3.2$ : wipe's force recipient is a potential incremental theme, allowing wipe to have either telic or atelic interpretations. The telic interpretation arises when the referent of the force recipient is a delimited entity, which can serve as an incremental theme and 'measure out' and bound the event. A telic interpretation may even be preferred, reflecting a general preference in English for giving telic interpretations to past events when not otherwise ruled out.

As noted in $\S 3$, wiping verbs, like surface contact verbs in general, can express other event participants as their object. One is the material participant, which is distinctive to wiping events. These options are discussed in $\S 6$.

\subsubsection{Accounting for the basic paradigms: hit}

Next I turn to the basic argument realization options characteristic of hit. This verb, like wipe, has a manner root which brings with it an effector, which 'instantiates' the manner, and a second participant, the surface or force recipient. For the same reasons as wipe, hit is found in unspecified object contexts, as in (36), as well as in transitive and conative contexts, as in (37) and (38). 
The golfer hit.

The golfer hit the ball.

(38) The golfer hit at the ball.

Another hallmark of hit is participation in the with/against alternation as in (39), an alternation that is found in slightly different form with wipe, as illustrated in (19). I assume the same analysis applies to the alternation as manifested by both verbs.

a. The boy hit the window with a stick.

b. The boy hit the stick against the window.

The with variant in (39a) involves the expression of an instrument with the activity event structure and should be accounted for by the argument realization rule that applies to instruments. The event structure of the against variant in (39b) has not received attention. Despite the presence of a locative phrase, I believe that (39b) is not a causative construction and hence does not receive a complex event structure; however, I leave it to future work to provide independent support for this claim. ${ }^{11}$ What matters is that hit allows an 'instrument' object as in (39b); this option is available as manner roots impose no constraints on their associated verb's object. ${ }^{12}$

As noted in \$3.2, hit's object, unlike wipe's, cannot be understood as an incremental theme, even when its referent is a bounded entity. I propose that this option is unavailable because the force recipient in a hitting event is conceptualized as a point. Thus, the force recipient cannot serve as a 'measure' for the event, so that hitting verbs are never incremental theme verbs. As also noted in \$3.2, hit also differs from wipe in being found in the possessor raising construction.

(40) a. Kelly hit me on the arm. (cf. Kelly hit my arm.)

b. * Kelly wiped me on the arm. (cf. Kelly wiped my arm.)

I attribute this difference too to the nature of the force recipient. As the force recipient is conceptualized as a point, it is taken to be an undifferentiated whole. Thus, contact with—or more precisely imparting a force to-any single inalienable part of a force recipient is considered to be imparting a force to the whole entity; hence, Kelly hit my arm implies Kelly hit me (on the arm).

11 Determining the causative status of (39b) is nontrivial. The standard diagnostics for a causative event structure are sensitive to the presence of a result state; however, it is not clear the against PP describes the result location of the stick, so these diagnostics are inapplicable. This point emerges most clearly with wiping verbs: in Sam wiped a damp cloth over the table, the cloth is not then 'over' the table.

12 The account here explains why the instrument object option is available; however, there is more to be investigated as not all manner verbs allow 'instrument' objects (e.g., The cook stirred the batter with a wooden spoon, but *The cook stirred a wooden spoon against/over/into the batter). This option most likely relates to the nature of the root. Surface contact verbs may lexicalize necessary contact in a way that other manner verbs do not; further, with surface contact verbs, the instrument could be seen as a proxy for the effector with respect to making the contact. 
Verb meaning revisited

\section{Expanding the paradigms: Building complex event structures}

Manner verbs, including hitting and wiping verbs, are also found in constructions expressing scalar changes, as in the resultative construction Sam wiped the table clean. In such constructions, the scalar change is explicitly specified in a result XP. These constructions include some of the further argument realization options from §3: constructions with nonselected objects and with the material argument of wiping verbs. In $\S 6.1$ I discuss complex event structures in general. In $\$ 6.2$ and $\$ 6.3$ I turn to the complex event constructions found with wipe, hit, and comparable verbs. I show how differences in an agent's purpose in carrying out a hitting or wiping event underlie the similarities and differences in the types of complex event structures - and hence argument realization options - available to verbs of each type.

\subsection{On the nature of complex event structures}

A causative event of scalar change can be expressed by a sentence whose verb has a state root, as in The boy broke the window. Alternatively, the two subevents of a causative event of scalar change can be expressed by distinct lexical predicates, as in Sam wiped the table clean. The causing subevent-the activity component of the event structure - is expressed by a manner verb whose root is associated with this subevent. The scalar change component of the causative event structure-the caused or 'result' subevent-is expressed by a result XP, which specifies the key components of the scalar change. ${ }^{13}$ Such event structures are taken to be compositionally created by a process of template augmentation in Rappaport Hovav \& Levin 1998: 111: the 'augmented' causative event structure is built onto a simple activity event structure with a manner root through combination with a scalar change event structure.

In the constructions realizing such event structures, a result XP introduces the event of scalar change. Result APs, which have adjective heads lexicalizing a state, can only express scalar changes involving a property scale, as in Kim pounded the metal flat. Result PPs express path scales, and such paths may be instantiated in two abstract semantic fields in the sense of Jackendoff (1983), his positional and identificational fields. Paths in the positional field instantiate a literal understanding of a path as a series of contiguous locations in physical space. Paths in the identificational field are figurative: they are defined as a series of contiguous locations in a space of property states. Result PPs of this second type provide

13 Result XPs can also fill out a scale partially lexicalized in a state root as happens with some change of state verbs. In Terry broke the vase to smithereens, the result XP further specifies the precise endpoint of a scale that is partially specified in the root. Result XPs found with verbs with state roots cannot introduce an additional scale due to the constraint that a well-formed event structure can include only one scalar change (Goldberg 1995; Tenny 1994). Such XPs are not discussed further. 
an alternate way of specifying a scalar change. Such paths can also express the transformation of an entity from one form to another, as discussed in $\S 6.2$ and $§ 6.3$.

The patient realization condition of $\$ 4$ holds equally of scalar changes expressed by result XPs, such as those standing in for the result subevent in a causative event structure. Thus, the event participant such a scalar change is predicated of must be expressed and then only as an object. However, the activity subevent in a causative event structure does not impose such a constraint on the force recipient, if one is introduced by the verb root. Thus, unless the patient of the scalar change coincides with the force recipient, the construction as a whole may have an object that is not selected by its verb, as exemplified and discussed in $\S 6.2$ and $\S 6.3$.

Researchers have established a well-formedness condition on constructions that instantiate complex event structures such as lexical causatives and resultatives (Fodor 1970; Goldberg 1995: 194-195; McCawley 1978; Pinker 1989: 66; Shibatani 1976; Smith 1970). They require a tight relation between the constituent subevents, usually understood as direct causation (Wolff 2003: 5, but see Neeleman \& van de Koot 2012 for some cautions). Thus, the state expressed in the result subevent must be one that can be directly caused by the causing subevent, i.e. able to be brought about by the relevant manner. Focusing on surface contact events, actors may make contact with a force recipient-i.e. a surface - in many ways; the nature of the contact is often driven by the actor's goal, and there can be various goals that drive such events. Hitting events are usually carried out with the intention of damaging, deforming, or causing a change to the material integrity (to use Hale \& Keyser's 1987 term) of a force recipient, or if the force recipient is an animate entity even to cause a psychological effect (Dowty 1991: 596; Lundquist \& Ramchand 2012: 230). Wiping events are usually carried out with the intention of cleaning or otherwise changing the state of a surface, typically by removing impurities or other material from it. Further, certain manners are conventionally associated with the achievement of particular results: wiping is a way of cleaning a counter or other household surface, sweeping is a way of cleaning a floor or walk, and pounding is a way of flattening a surface. These associations ensure that a complex event structure with a hitting or wiping root in its activity subevent meets the direct causation condition.

Speakers draw on their knowledge of such manner-result associations in building complex event structures; however, a manner root's semantic content does not include the results that the manner can be used to achieve. If it did, a relevant result state should be entailed in every use of the associated verb, but no result need be entailed as shown by (8b), repeated as (41), although one may be, as shown by (42). These results, then, are part of a speaker's world knowledge about the relevant actions.

(41) The vandal hit the flower pot with a rock, but nothing happened to it.

(42) The vandal hit the flower pot with a rock, and it broke. 
Verb meaning revisited

I now show how the precise form that attested complex event constructions with hitting and wiping verbs take is influenced by what speakers know about the intended goals of the actions encoded in their roots. The diversity of complex event constructions that hitting and wiping verbs are found in has two sources. First, as certain manners can be used to achieve more than one result, verbs associated with some manner roots may be found in complex event constructions with result XPs expressing more than one type of scalar change. Second, certain types of scalar changes can be expressed by either result APs or PPs.

\subsection{Complex events with wiping roots}

Due to its manner root, wipe may be used in the expression of causative events of scalar change with wipe's root in the activity subevent. The scalar change expressed by the result subevent must be one that can be directly caused by wiping, and most often it expresses one of the typical goals that an agent has in carrying out such an event. Wiping events are usually performed to clean surfaces, often by removing impurities found on them, and, in fact, wiping verbs are combined with various types of result XPs that express such goals. I now review some options.

I begin with result PPs introducing literal spatial paths. They may convey either a removing or a putting event according to whether the PP denotes the source of motion as in (43) or the goal as in (44). Such PPs are predicated of an NP denoting the stuff that is being moved from the surface-what is called the material in $\$ 3.2-$ and, thus, these PPs serve to introduce such an argument.

(43) Sam wiped crumbs off the table.

(44) Sam wiped the crumbs into the sink.

When the path PP specifies a source as in (43), then the source is necessarily understood as the surface from which material is being removed. Thus, here the surface is expressed in a from phrase, rather than as the verb's object. When the path PP specifies a goal as in (44), the source is typically left implicit, but is still understood to be the surface. The surface does not need to be expressed as discussed in §5.2.2. In (43) and (44), the material, as the argument that the path PP is predicated of, must be expressed as the object, but in both it is a nonselected object of the verb.

Turning to more abstract types of paths, another option is for the path PP to introduce an entity created from the material on the surface, as in (45). Here the goal specifies the transformed form of the material, a transformation brought about by the application of the manner to the surface. This path again licenses the expression of the material, which must then be expressed as the object; again, the surface is left unexpressed.

(45) Sam wiped the crumbs into a pile. 
Wiping events are typically performed to clean or otherwise improve surfaces, and the intended result can be explicitly expressed in a result subevent that specifies a scalar change in a property of the surface. The property scale may be introduced by a figurative path PP (in the identificational field), as in (46), or an AP, as in (47).

Sam wiped the table to a glossy shine.

Sam wiped the table clean.

In these examples, the introduced property scale is predicated of the surface, and it specifies the change in the surface brought about by the root's manner. Since the surface has a scalar change predicated of it, it cannot be omitted (*Sam wiped clean on an unspecified object interpretation). Alternatively, as the manner root does not require the surface to be expressed, it should be possible for a result XP to introduce a state holding of some entity other than the surface as a result of the verb's manner, and, in fact, result XPs can be found predicated of nonselected arguments, with the surface left implicit. Thus, (48) has a reading where Sam is understood to be scrubbing some surface — say, a bathtub — and as a result her hands become raw. Here the result is a direct side effect of scrubbing the surface in order to bring about the more conventional result of cleaning it. Thus, the direct causation condition is satisfied. (A selected object interpretation of (48), 'Sam scrubbed her hands causing them to be become raw', is also available and is perhaps the most accessible interpretation in an out-of-the-blue context.)

Sam scrubbed her hands raw.

In summary, wipe is found in a range of complex event constructions. These options arise because of the two types of XPs available to express results-APs and PPs, including literal and figurative instances of the latter-and because of the various types of results that wiping events can bring about.

\subsection{Complex events with hitting roots}

As with wipe, hit and hitting verbs more generally are found in various types of constructions expressing causative events of scalar change where the scalar change is externally introduced. The spectrum of options arises from the types of results that forceful contact with a surface, i.e. a hitting event, can be used to bring about. These include damage to or displacement of the force recipient.

Again, I begin with literal path PPs. Such PPs can be predicated of the force recipient to describe an event where the impact with this entity imparts a force to it, causing it to move along a trajectory defined by the path PP, as in (49).

(49) Kim hit the ball into the playground. 
Verb meaning revisited

(49) has a 'selected object' interpretation as the force recipient moves. It contrasts with the wipe example (44): it also has a literal path PP, but has a 'nonselected object' interpretation as the PP is predicated of the material. Abstract path PPs are also found with hitting verbs, as in (50) with pound, which is the analogue of the wipe sentence (45). (50) describes an event of transforming the force recipient into the form specified in the PP by deforming it via the application of force.

(50) Kim pounded the metal into a tray.

Result XPs, whether APs or figurative path PPs, can also introduce a scalar change in a property of an entity that is directly caused by hitting. As with wipe, these result XPs can be predicated of the force recipient, as in (51), or they can introduce a nonselected object which the result is predicated of - another entity which the hitting impinges upon-as in (52), parallel to (48) with wipe.

(51) Kim pounded the metal flat.

(52) Kim drummed her fingers raw.

The options found with hit partially overlap with those found with wipe. The verb hit is not found in removing constructions because its lexicalized manner is not typically used to remove impurities from a surface. In contrast, hit is used to describe the causation of ballistic motion as in (49) because contact at a point can impart a force to an entity setting it in motion; however, wipe is not used in this way, presumably because its action pattern does not have this effect. Thus, although both hit and wipe are found in complex event constructions, the specific constructions reflect the different goals that hitting and wiping are used to bring about.

\section{Conclusion}

Result roots are systematically more restricted in their grammatical distribution than manner roots: there are many constructions where they are not found, but manner roots are. To account for these differences Rappaport Hovav \& Levin $(1998,2010)$ propose that roots have a grammatically relevant ontological category - that is, a facet of their semantic content that is grammatically privileged.

In this paper, I take a first look at further distributional differences among verbs. Although manner verbs have a wider distribution than result verbs, there are also pervasive and systematic distributional differences among them, which suggest there are linguistic generalizations behind them. Using hit and wipe as examples, I show that these two verbs share considerably more properties than manner hit and result break do, but each one nevertheless has a distinctive distributional signature. I argue that certain differences between hit and wipe can be traced to another facet of the semantic content of their roots: whether the manner involves contact at a point or 
a region. To the extent that this proposal provides insight into the distributional signatures of these two verbs, it reaffirms that the root plays a part in determining argument realization options.

I attribute the ability of hitting and wiping verbs to be found in complex event constructions to their manner roots; however, I propose that the range of attested instances of such constructions draws on a speaker's knowledge of the intended purposes of hitting and wiping events. Thus, the attested constructions have those XPs that describe results that these events can directly bring about. As discussed in $\S 6.1$, knowledge of such manner-result associations is not part of a root's semantic content: hitting and wiping verbs do not entail that the actions they denote bring about a specific result. Furthermore, although $\S 6.2$ and $\S 6.3$ lay out a range of attested result XPs found with both hit and wipe, these represent options that involve the most conventionally attested results. Other possibilities should be available in certain contexts, as long as the direct causation condition is met. Thus, properties of event structure and argument realization allow complex event constructions as an argument realization option, while non-linguistic knowledge about the intended goals of certain manners may influence the forms that the complex event constructions take. Thus, I hope this work contributes to the understanding of the locus of the interface between grammatical and world knowledge, part of what is called the Conceptual-Intentional (CI) interface in Minimalist work.

I have argued that the notions of point and region number among the grammatically privileged facets of a root's semantic content as they figure in the explanation argument realization options. I end this paper by raising a critical question: Is there a hallmark of those semantic properties that matter to language? Why do the notions of point and region bear on argument realization, while other facets of manner of surface contact such as intensity and iteration of contact apparently do not? Levin, Song \& Atkins (1997) find that among sound emission verbs, the pitch, volume, and duration of the sound-dimensions that seem comparable to intensity and iteration of contact-do not affect a verb's argument realization options either. However, the mode of production of a sound matters: whether a sound is produced via external contact or not affects whether it can be directly caused and hence whether the related verb allows causative uses. This property, then, bears on causation, a notion known to be both grammatically and cognitively relevant. Contact is often a necessary condition for direct causation, whether for sound emission events or complex causative events involving hitting and wiping; thus, it is not suprising that contact matters to argument realization. Although many proposed semantic determinants of argument realization are causal in nature, the notions of point and region, which differentiate among surface contact events, do not obviously qualify as causal. Nevertheless, they are cognitively relevant notions critical to our understanding of space. This study shows that they too matter to argument realization. 
Verb meaning revisited

\section{References}

Acedo-Matellán, Víctor \& Jaume Mateu. 2014. From syntax to roots: A syntactic approach to root interpretation. In Artemis Alexiadou, Hagit Borer \& Florian Schäfer (eds.), The Syntax of Roots and the Roots of Syntax, 14-32. Oxford, UK: Oxford University Press.

Alexiadou, Artemis \& Elena Anagnostopoulou. 2013. Manner vs. result complementarity in verbal alternations: A view from the clear-alternation. In 42nd Annual Meeting of the Northeastern Linguistics Society (NELS), 39-52. Amherst, MA: Graduate Linguistics Student Association, University of Massachusetts.

Alexiadou, Artemis, Elena Anagnostopoulou \& Florian Schäfer. 2015. External Arguments in Transitivity Alternations. Oxford, UK: Oxford University Press.

Beavers, John \& Andrew Koontz-Garboden. 2012. Manner and result in the roots of verbal meaning. Linguistic Inquiry 43(3). 331-369.

Borer, Hagit. 2003. Exo-skeletal vs. endo-skeletal explanations: Syntactic projections and the lexicon. In John Moore \& Maria Polinsky (eds.), The Nature of Explanation in Linguistic Theory, 31-67. Stanford, CA: CSLI Publications.

Borer, Hagit. 2005. Structuring Sense II: The Normal Course of Events. Oxford, UK: Oxford University Press.

Brisson, Christine. 1994. The licensing of unexpressed objects in English verbs. In 30th Annual Meeting of the Chicago Linguistic Society (CLS), 90-102. Chicago, IL: Chicago Linguistic Society, University of Chicago.

Dowty, David R. 1979. Word Meaning and Montague Grammar. Dordrecht: Reidel.

Dowty, David R. 1991. Thematic proto-roles and argument selection. Language 67(3). 547-619.

Fillmore, Charles J. 1970. The grammar of hitting and breaking. In Roderick A. Jacobs \& Peter S. Rosenbaum (eds.), Readings in English Transformational Grammar, 120-133. Waltham, MA: Ginn.

Fodor, Jerry A. 1970. Three reasons for not deriving kill from cause to die. Linguistic Inquiry 1. 429-438.

Ghomeshi, Jila \& Diane Massam. 1995. Lexical/syntactic relations without projection. Linguistic Analysis 24. 175-217.

Goldberg, Adele E. 1995. Constructions: A Construction Grammar Approach to Argument Structure. Chicago, IL: University of Chicago Press.

Grimshaw, Jane. 2005. Words and Structure. Stanford, CA: CSLI Publications.

Hale, Ken \& Samuel Jay Keyser. 1987. A view from the middle. Lexicon Project Working Papers 10.

Harley, Heidi. 2005. How do verbs get their names? Denominal verbs, manner incorporation and the ontology of verb roots in English. In Nomi Erteschik-Shir \& Tova Rapoport (eds.), The Syntax of Aspect, 42-64. Oxford, UK: Oxford 
University Press.

Harley, Heidi. 2010. A Minimalist approach to argument structure. In Cedric Boeckx (ed.), The Oxford Handbook of Linguistic Minimalism, 426-447. Oxford, UK: Oxford University Press.

Hay, Jennifer, Christopher Kennedy \& Beth Levin. 1999. Scalar structure underlies telicity in 'degree achievements'. In Semantics and Linguistic Theory (SALT) 9, 127-144. Ithaca, NY: Cornell Linguistics Circle Publications, Cornell University. Hoekstra, Teun. 1992. Aspect and Theta Theory. In Ignacio M. Roca (ed.), Thematic Structure: Its Role in Grammar, 145-174. Berlin: Mouton de Gruyter.

Hook, Peter E. 1983. The English abstrument and rocking case relations. In 19th Annual Meeting of the Chicago Linguistic Society (CLSL), 183-194. Chicago, IL: Chicago Linguistic Society, University of Chicago.

Jackendoff, Ray S. 1983. Semantics and Cognition. Cambridge, MA: MIT Press. Jackendoff, Ray S. 1990. Semantic Structures. Cambridge, MA: MIT Press.

Kennedy, Chris \& Beth Levin. 2008. Measure of change: The adjectival core of degree achievements. In Louise McNally \& Chris Kennedy (eds.), Adjectives and Adverbs in Semantics and Discourse, 156-182. Oxford, UK: Oxford University Press.

Kratzer, Angelika. 2000. Building statives. In 26th Annual Meeting of the Berkeley Linguistics Society (BLS): General Session and Parasession on Aspect, 385-399. Berkeley, CA: Berkeley Linguistics Society, University of California, Berkeley.

Krifka, Manfred. 1998. The origins of telicity. In Susan Rothstein (ed.), Events and Grammar, 197-235. Dordrecht: Kluwer.

Levin, Beth. 1993. English Verb Classes and Alternations: A Preliminary Investigation. Chicago, IL: University of Chicago Press.

Levin, Beth. 1999. Objecthood: An event structure perspective. In 35th Annual Meeting of the Chicago Linguistic Society (CLS), Part 1: The Main Session, 223-247. Chicago, IL: Chicago Linguistic Society, University of Chicago.

Levin, Beth. 2015. Event encoding in a crosslinguistic perspective II: The encoding of hitting events across languages. Handout, LSA Institute Course 319.

Levin, Beth \& Malka Rappaport Hovav. 1991. Wiping the slate clean: A lexical semantic exploration. Cognition 41. 123-151.

Levin, Beth \& Malka Rappaport Hovav. 1999. Two structures for compositionally derived events. In Semantics and Linguistic Theory (SALT) 9, 199-223. Ithaca, NY: Cornell Linguistics Circle Publications, Cornell University.

Levin, Beth, Grace Song \& B.T.S. Atkins. 1997. Making sense of corpus data. International Journal of Corpus Linguistics 1. 23-64.

Lieber, Rochelle. 2004. Morphology and Lexical Semantics. Cambridge, UK: Cambridge University Press.

Lundquist, Björn \& Gillian Ramchand. 2012. Contact, animacy and affectedness 
Verb meaning revisited

in Germanic. In Peter Ackema, Rhona Alcorn, Caroline Heycock \& Dany Jaspers (eds.), Comparative Germanic Syntax: The State of the Art, 223-248. Amsterdam: John Benjamins.

Marr, David \& Lucia Vaina. 1982. Representation and recognition of the movements of shapes. In Royal Society of London B 214, 501-524. London: The Royal Society Publishing.

Mateu, Jaume. 2012. Structure of the verb phrase. In José Ignacio Hualde, Antxon Olarrea \& Erin O'Rourke (eds.), The Handbook of Hispanic Linguistics, 333353. Chichester, UK: Wiley.

Mateu, Jaume \& Víctor Acedo-Matellán. 2012. The manner/result complementarity revisited: A syntactic approach. In María Cristina Cuervo \& Yves Roberge (eds.), The End of Argument Structure, 209-228. Bingley, UK: Emerald Books.

McCawley, James D. 1971. Prelexical syntax. In Report of the 22nd Annual Roundtable Meeting on Linguistics and Language Studies, 19-33. Washington, DC: Georgetown University Press.

McCawley, James D. 1978. Conversational implicature and the lexicon. In Peter Cole (ed.), Syntax and Semantics 9: Pragmatics, 245-259. New York: Academic Press.

Morgan, Jerry L. 1969. On arguing about semantics. Papers in Linguistics 1. 245-259.

Neeleman, Ad \& Hans van de Koot. 2012. The linguistic expression of causation. In Martin Everaert, Marijana Marelj \& Tal Siloni (eds.), The Theta System: Argument Structure at the Interface, 20-51. Oxford, UK: Oxford University Press.

Pesetsky, David. 1995. Zero Syntax. Cambridge, MA: MIT Press.

Pinker, Steven. 1989. Learnability and Cognition: The Acquisition of Argument Structure. Cambridge, MA: MIT Press.

Ramchand, Gillian. 1997. Aspect and Predication. Oxford, UK: Clarendon Press.

Ramchand, Gillian. 2008. Verb Meaning and the Lexicon: A First-Phase Syntax. Cambridge, UK: Cambridge University Press.

Ramchand, Gillian. 2014. On structural meaning vs conceptual meaning in verb semantics. Linguistic Analysis 39. 207-243.

Rappaport Hovav, Malka. 2014. Building scalar changes. In Artemis Alexiadou, Hagit Borer \& Florian Schäfer (eds.), The Syntax of Roots and the Roots of Syntax, 259-281. Oxford, UK: Oxford University Press.

Rappaport Hovav, Malka. In press. Grammatically relevant ontological categories underlie manner/result complementarity. In Israel Association for Theoretical Linguistics (IATL) 32, Cambridge, MA: MIT Working Papers in Linguistics.

Rappaport Hovav, Malka \& Beth Levin. 1998. Building verb meanings. In Miriam Butt \& Wilhelm Geuder (eds.), The Projection of Arguments: Lexical and 
Compositional Factors, 97-134. Stanford, CA: CSLI Publications.

Rappaport Hovav, Malka \& Beth Levin. 2001. An event structure account of English resultatives. Language 77. 766-797.

Rappaport Hovav, Malka \& Beth Levin. 2005. Change of state verbs: Implications for theories of argument projection. In Nomi Erteschik-Shir \& Tova Rapoport (eds.), The Syntax of Aspect, 274-286. Oxford, UK: Oxford University Press.

Rappaport Hovav, Malka \& Beth Levin. 2010. Reflections on manner/result complementarity. In Malka Rappaport Hovav, Edit Doron \& Ivy Sichel (eds.), Lexical Semantics, Syntax, and Event Structure, 21-38. Oxford, UK: Oxford University Press.

Richardson, John F. 1983. Smash bang. In 9th Annual Meeting of the Berkeley Linguistics Society (BLS), 211-222. Berkeley, CA: Berkeley Linguistics Society, University of California, Berkeley.

Segal, Zehavit \& Idan Landau. 2012. Clear from and clear of: The asymmetric syntax of detaching. The Linguistic Review 29. 223-278.

Shibatani, Masayoshi. 1976. The grammar of causative constructions: A conspectus. In Masayoshi Shibatani (ed.), Syntax and Semantics 6: The Grammar of Causative Constructions, 1-40. New York: Academic Press.

Smith, Carolta S. 1970. Jespersen's 'move and change' class and causative verbs in English. In Mohammed Ali Jazayery, Edgar C. Polomé \& Werner Winter (eds.), Linguistic and Literary Studies in Honor of Archibald A. Hill, Vol. 2, Descriptive Linguistics, 101-109. The Hague: Mouton.

Stringer, David. 2011. Phonomimesis and directional predication in the acquisition of L1 Japanese and L2 English. Japanese and Korean Linguistics 18. 16-27.

Tenny, Carol L. 1992. The aspectual interface hypothesis. In Ivan A. Sag \& Anna Szabolcsi (eds.), Lexical Matters, 1-27. Stanford, CA: CSLI Publications.

Tenny, Carol L. 1994. Aspectual Roles and the Syntax-Semantics Interface. Dordrecht: Kluwer.

Van Valin, Robert D. \& David P. Wilkins. 1996. The case for 'effector': Case roles, agents, and agency revisited. In Masayoshi Shibatani \& Sandra A. Thompson (eds.), Grammatical Constructions, 289-322. Oxford, UK: Clarendon Press.

Vendler, Zeno. 1957. Verbs and times. Philosophical Review 56. 143-160.

Wolff, Phillip. 2003. Direct causation in the linguistic coding and individuation of causal events. Cognition 88. 1-48. 
Verb meaning revisited

Beth Levin

Department of Linguistics

Stanford University

Stanford, CA 94305-2150

beth.levin@stanford.edu 